\title{
Configurações
}

Revista de sociologia

\section{Clubbing e construções identitárias de género: proposta de um quadro analítico}

Identity constructions of gender in clubbing: proposal of an analytical framework

Constructions identitaires de genre dans le clubbing: Proposition d'un cadre analytique

\section{Pedro Bóia, Lígia Ferro e João Texeira Lopes}

\section{(2) OpenEdition}

\section{Journals}

Edição electrónica

URL: http://journals.openedition.org/configuracoes/2652

DOI: $10.4000 /$ configuracoes. 2652

ISSN: $2182-7419$

\section{Editora}

Centro de Investigação em Ciências Sociais

\section{Edição impressa}

Data de publição: 30 Junho 2015

Paginação: 9-29

ISBN: 1646-5075

ISSN: 1646-5075

\section{Refêrencia eletrónica}

Pedro Bóia, Lígia Ferro e João Texeira Lopes, « Clubbing e construções identitárias de género: proposta de um quadro analítico », Configurações [Online], 15 | 2015, posto online no dia 01 setembro 2015, consultado o 30 abril 2019. URL : http://journals.openedition.org/configuracoes/2652 ; DOI : $10.4000 /$ configuracoes. 2652

Este documento foi criado de forma automática no dia 30 Abril 2019 


\title{
Clubbing e construções identitárias de género: proposta de um quadro analítico
} $\left[\begin{array}{ll}F \theta \\ 2 A\end{array}\right.$

\author{
Identity constructions of gender in clubbing: proposal of an analytical \\ framework \\ Constructions identitaires de genre dans le clubbing: Proposition d'un cadre \\ analytique
}

Pedro Bóia, Lígia Ferro and João Texeira Lopes

\begin{abstract}
Este artigo pretende contribuir para os clubbing studies, propondo um modelo analítico delineado a partir de uma investigação dos processos de construção identitária de género - particularmente das mulheres - nas (sub)culturas associadas às festas de música electrónica de dança em Portugal. Sendo um texto quase exclusivamente teórico, é discutido um modelo de análise que, tendo emergido no âmbito de um projecto de investigação específico ${ }^{1}$, poderá ter potencial heurístico para o estudo de outras realidades do clubbing noutros espaços, culturas e países, considerando-se outras fracções do clubbing e respectivos subgéneros musicais. Para além de desenharmos uma grelha que servisse as metas deste projecto específico, foi também nossa intenção dar azo à "imaginação sociológica" construindo um modelo que possa ser usado em contextos de pesquisa diversos que não privilegiam necessariamente o género. A sua construção muito deve ao constante "vaivém" entre teoria e empiria (Lopes, 2000: 192), processo dialéctico imprescindível em qualquer estudo sociológico.

$\mathrm{O}$ campo dos estudos de género tem crescido exponencialmente em Portugal e ambicionamos que esta proposta contribua para o estudo das (sub)culturas, estimulando a reflexividade acerca das diferenças de género. Os objectivos empíricos específicos da investigação foram compreender a experiência das mulheres no clubbing, considerandose aspectos como o prazer e o hedonismo (enfatizados por Jackson, 2003; Malbon, 1999²), bem como o controlo
\end{abstract}


social versus a autonomia, a sexualidade, os usos de drogas, a gestão do risco, a violência.

Após uma discussão introdutória sobre género e teoria social, faremos uma revisão da literatura sobre 'subculturas', 'pós-subculturas' e 'culturas club'.

Formulando-se um quadro teórico de base híbrida, serão depois debatidas:

i) a necessidade de segmentar com precisão e especificar empiricamente e de um modo localizado quais as fracções do clubbing a estudar;

ii) a necessidade de proceder a uma efectiva intersecção entre variáveis (género, classe social, etnicidade, estruturação interna do clubbing, gosto);

iii) a importância de se considerar as trajectórias biográficas e de socialização das clubbers, bem como os processos de internalização, de modo a conseguir-se um aprofundamento da abordagem interseccional.

Finalmente, após a apresentação de breves exemplos dos resultados da investigação que originou este quadro teórico, será discutida a importância desta proposta para especificar empiricamente as experiências, configurações de género e feminilidades concretas, de modo a evitar-se a universalização indevida de uma só noção e experiência de "mulher clubber".

\section{Género e teoria social: pressupostos fundamentais}

Visando aprofundar a abordagem de género, este estudo centra-se nas identidades femininas. Na linha do que tem sido defendido no seio das ciências sociais, consideramos que o termo "sexo" serve unicamente para designar as diferenças biológicas e fisiológicas entre homens e mulheres, o que não satisfaz as pretensões de descortinar "a masculinidade ou a feminilidade convencionadas socialmente" (Ferreira, 2001: 49; cf., por ex., Anderson, 1997). Usamos, assim, o conceito de "género", que se refere ao carácter não natural mas antes construído da masculinidade e da feminilidade.

O enfoque analítico privilegia uma abordagem multidimensional das relações de poder. De Max Weber e Pierre Bourdieu retoma-se a indicação heurística de conceber níveis relativamente autónomos de recursos (capital económico, cultural, social, político e simbólico), sem esquecer as suas múltiplas sobredeterminações e diferentes actualizações, quer nos campos em que as práticas operam (nível macrossociológico), quer nos quadros de interaç̧ão em que se exercitam (nível meso e micro-sociológico).

Das abordagens pós-estruturalistas retemos as concepções multiformes de dominação mas também as possibilidades de emancipação, sem estabelecer, a priori, qualquer determinismo simplista ou centralidade exclusiva. São consideradas variáveis estruturais como classe social, género, etnicidade. No entanto, são sublinhadas, por opção analítica de partida, a variável género e as suas modalidades de inter-relação com os processos de dominação/emancipação.

7 É fundamental, na concepção de agência feminina, a teoria da estruturação de Giddens (1996, 2000). Pensamos como Giddens que as estruturas não existem de "modo coisificado", como reificação exterior aos agentes, na mais pura herança durkheimiana. Há que acentuar a co-produção dos sujeitos e das estruturas, recusando versões positivistas que encaram os agentes como tábua rasa ou cultural dopes. A vida social produz-se e reproduz-se pelo mesmo processo através do qual as estruturas (cuja ordem é virtual) se tornam instantâneas ou imanentes na e pela prática social, sendo, 
simultaneamente, a sua condição e o seu resultado. Realça-se, então, a consciência discursiva dos agentes e as formas de linguagem mediante as quais aquela é expressa, particularmente nos espaços-tempo dos quadros de interacção, unidade de observação e de análise, onde os conflitos de sentido são, igualmente, conflitos corporais e performativos. Investimentos discursivos, verbais e/ou não verbais merecem especial atenção. As mulheres, enquanto agentes, são, pois, pensadas nesta dupla perspectiva: dentro dos contextos e fora deles, fugindo quer às teorias que concebem o indivíduo independentemente da sua situação nos espaços sociais, quer às visões impessoais que recusam a capacitação dos agentes em pensar e modificar tais contextos, ganhando, face a eles, uma distância reflexiva.

8 Esta abordagem fi caria incompleta se não avançássemos na direcção de uma agência feminina enquanto aceitação analítica da circunstância de que as mulheres são agentes sociais, "envolvidas num sistema social, sistémico e simbólico, edificado na continuidade, contradição e mudança" (Arnot e Dillabough, 2002).

Um terceiro procedimento é necessário: a agência feminina distancia-se das visões essencialistas e do pensamento único identitário. Afirmamos assim a nossa preocupação com as heterogeneidades - não só as acções são plurais, como as suas disposições se revelam contraditórias, tensas, compósitas (Lahire, 2005).

10 Finalmente, importa ainda dar um quarto passo: considerar a radicalidade da categoria "mulher" por oposição, quer às concepções abstractas (presentes, por exemplo, na concepção de esfera pública de Habermas (1984), onde o arbitrário cultural e a violência simbólica da ordem masculina hegemónica repousam num conceito sem género - o de cidadão autónomo, dissociado das condições sociais da sua produção e sem identidade substantiva, espécie de lugar vazio da cidadania), quer às concepções neoliberais e individualistas. Tal significa pensar num colectivo de agentes femininos heterogéneos mas dotados de intencionalidade política, social, cultural e simbólica, capazes de agir na e com a diferença, através de consensos dialógicos e provisórios. Afirma Young: "Sem conceptualizar as mulheres, de alguma forma, como um grupo, não é possível conceptualizar a opressão como um processo institucional, sistemático e estruturado" (1995: 192). Ao mesmo tempo, há que abdicar do ponto de vista soberano, da pretensão de poder falar com legitimidade de todas as experiências femininas.

\section{Género, subculturas e clubbing}

11 Já no clássico livro Resistance through Rituals, obra-chave do paradigma das subculturas desenvolvida pelo Centre for Contemporary Cultural Studies (CCCS) de Birmingham e originalmente publicada em 1976, McRobbie e Garber (2006) alertavam para a falha daquele modelo em termos de género, nomeadamente a ausência das raparigas das análises subculturais. Estas autoras denunciavam que as pesquisas, os pesquisadores e os pesquisados estavam submersos numa lógica dominante masculina (Lincoln, 2004).

12 Enriquecendo a teoria assente no conceito de 'subcultura', McRobbie e Garber acrescentam assim a variável género à de classe social, privilegiada naquela perspectiva. Mostram como a atenção empírica ao que chamam "cultura de quarto" permite colmatar a invisibilidade das raparigas nas análises subculturais. Fazem-no considerando os papéis subculturais por elas desempenhados na esfera mais privada, alternativa ao espaço 
público dominado pelo género masculino. A análise alarga-se, assim, à respectiva 'cultura de interiores' (o quarto, dentro de casa).

Entretanto, ao longo das várias décadas que passaram desde a publicação de Resistance through Rituals, a participação das mulheres no espaço público intensificou-se, sendo hoje mais presente e activa no clubbing do que o era nas 'antigas' subculturas. Na esfera do lazer houve, assim, um movimento das mulheres do lar e do quarto para os clubes ${ }^{3}$. Apesar disso, nos inícios do século XXI, Pini (2001) e Hutton (2004, 2006) apontavam que, no âmbito da sua relação com as práticas de lazer, as mulheres continuavam a ser predominantemente estudadas no âmbito da cultura de interiores.

O alerta estava dado, de novo, para a relativa invisibilidade das mulheres nas análises das culturas club contemporâneas (Pini, 2001: 10; Hutton, 2006: 1). Tal como há quarenta anos, no caso das análises enquadradas pelo paradigma das subculturas, também o estudo das club cultures se centrava e se restringia, tacitamente, à experiência dos homens. A negligência das experiências das mulheres é tanto mais grave quanto a sua participação no clubbing parece ser, proporcionalmente, mais intensa do que nas subculturas das décadas anteriores.

Pini salienta que sair à noite, ingerir álcool ou até drogas, bem como a expressão da sexualidade menos sujeita a constrangimentos, deixaram de constituir práticas exclusivamente masculinas (Pini, 2001: 10-13). A narrativa da 'aventura' aparece nos discursos das mulheres clubbers por ela entrevistadas.

Aí, são significativas as noções de liberdade e libertação associadas à emergência de novas feminilidades (Ibidem: 14-15) ${ }^{4}$. No entanto, esta autora também realça a ideia do clubbing como propiciador de um sentimento comunitário de pertença, ao constituir uma espécie de novo 'lar' ('home') alternativo à casa (Ibidem: 15-16)4. 'Loucura' e 'confusão' substituem a estabilidade e o fechamento do lar e da cultura de interiores descrita por McRobbie e Garber (2006) décadas antes - Pini interpreta os discursos das clubbers sugerindo que, nos espaços de clubbing, elas se sentem em 'casa' (Pini, 2001: 15). Pini considera assim que, como parte dos processos de reconfiguração pelos quais passa hoje a feminilidade nas sociedades ocidentais contemporâneas, as culturas club associadas à música electrónica de dança constituem espaços privilegiados de desafio às feminilidades tradicionais e de experimentação de novas feminilidades. Mais do que isso, 'losing it' na pista de dança, segundo Pini (2001), permite às mulheres uma "resolução mágica" das contradições e da confusão que deriva dessas aceleradas reconfigurações de género. Por sua vez, Hutton $(2004,2006)$ propõe, contrariamente ao discurso dominante, que o risco (inerente ao uso "recreativo" de certas drogas e à sexualidade) pode ser um recurso positivo para a construção identitária das mulheres.

\section{Da teoria clássica das subculturas às pós- subculturas e culturas club}

17 Para a formulação do quadro teórico proposto, começaremos por discutir a abordagem subcultural clássica e as transformações sociais e económicas que levaram à emergência das chamadas club cultures e das pós-subculturas, bem como as respectivas implicações de género. Serão debatidos aspectos da teoria clássica das subculturas que a nosso ver continuam a ser relevantes, bem como as perspectivas mais recentes, considerando-se as críticas e os alargamentos face à teoria subcultural. Em resultado, é formulado o conceito 
híbrido de (sub)cultura club, não filiado numa única destas teorias mas antes possuidor da plasticidade necessária para captar empiricamente a complexidade das realidades do clubbing.

\subsection{O paradigma subcultural clássico da escola de Birmingham}

A emergência das culturas juvenis surgia, aos olhos dos autores da 'escola de Birmingham' do CCCS dos anos 70, como um dos aspectos mais distintos e 'espectaculares' da cultura britânica do pós-Segunda Guerra Mundial, suscitando questões sobre o carácter contraditório e contestado da mudança cultural, bem como sobre a diversidade de formas de "resistência" que tomavam forma (Hall e Jefferson, 20065: viii). Central a esta perspectiva, enformada por um estruturalismo marxista, era a intenção de estabelecer conexões entre os fenómenos subculturais e uma análise histórica social e cultural geral da formação social, procurando aí encontrar 'homologias' (Ibidem: viii-ix) ${ }^{6}$.

A importância que esta perspectiva atribuía à cultura e à sua dimensão

simbólica, no contexto da sociologia dominante de então, embora não procurando superar os princípios básicos da sociologia marxista, dão-lhe um lugar de relevo na 'viragem cultural' nas ciências sociais (Ibidem: ix). Na procura de homologias e conexões, a variável classe social e a consideração das esferas da família, da escola e do trabalho, adquirem um lugar central (Lincoln, 2004: 94).

As subculturas juvenis eram, pois, conceptualizadas (porventura algo idealisticamente) como formas de "resistência" face à cultura dominante, ou seja,como expressões autênticas da juventude da classe operária, descomprometidas relativamente a lógicas de comercialismo. Em Learning to Labour, Willis (1977) conceptualiza as subculturas dos rapazes da classe operária como formas de "resistência" à cultura dominante da escola, enquanto Hebdige (1979) analisa o estilo punk vendo-o também como resistência através da 'bricolage' subjacente ao slogan do movimento ("DIY" - "Do it yourself"). Por sua vez, Phil Cohen (1997 [1972]) perspectiva as subculturas juvenis como lugares que permitem "resoluções mágicas" de contradições de classe entre a cultura operária dos pais e outras formas culturais.

As análises subculturais centram-se nas culturas dos jovens da classe operária, procurando 'homologias' entre estas e a estrutura de classes sociais. Até meados dos anos 80 parece que era, até certo ponto, mais fácil encontrar linearidades entre a estrutura social de classes e as subculturas, nomeadamente entre a classe operária e as respectivas subculturas juvenis.

\subsection{0 contexto neoliberal e a emergência das club cultures}

19 A emergência do neoliberalismo em finais da década de 1970 e inícios da de 1980 e a correspondente afirmação do mercado, associados a um maior individualismo, marcam um ponto de viragem na configuração das culturas juvenis (Redhead, 1997; Hall e Jefferson, 2006). Para compreendermos as culturas juvenis posteriores a meados dos anos 1980 há que considerar o fenómeno de internacionalização e globalização do desporto e da música (Redhead, 1997: x). A crescente globalização das subculturas pode ser, ainda, relacionada com a emergência das novas economias culturais e regimes de acumulação global na década de 1980 (Roberts, 2005: 575, apud Hall e Jefferson, 2006: xxi).

A nova fluidez e o hibridismo das formações culturais juvenis, bem como a maior dificuldade em se estabelecerem conexões estruturais levaram à reconceptualização dos 
fenómenos anteriormente entendidos como 'subculturas', como 'neotribos' (Maffesoli, 1987; Bennett, 1999), 'novos movimentos sociais' (Martin, 2004), 'pós-subculturas' (Muggleton, 1997, 2000; Bennett e KahnHarris, 2004) ou 'culturas club' (Redhead, 1997; Redhead et al., 1997) (cf. Hall e Jefferson, 2006: xix).

Estas teorizações, diferentes do quadro inicial da escola de Birmingham e mais ou menos pós-modernas conforme cada autor, baseiam-se na ideia fundamental de que as variáveis estruturais clássicas como a classe social perderam importância relativamente ao gosto. As novas perspectivas entendem agora o gosto (por um certo tipo de música, por exemplo) como uma variável difusa e fluida, ou seja, autónoma relativamente a condicionamentos classistas e como estando fortemente associada ao consumo (também ele autónomo). Estas seriam então culturas do gosto - isto é, baseadas na agregação, nos espaços do clubbing, de pessoas com características sociais diferentes mas com um gosto comum. São também de realçar o hedonismo e a identificação com valores boé-

mios, fenómenos vistos como tendo uma lógica de certo modo transclassista e associandose, pois, a processos de distinção social autonomizada da estrutura de classes e respectivos determinismos.

Inserido na corrente pós-subculturalista, Muggleton, para além de propor uma abordagem neoweberiana, faz uma actualização pós-moderna da semiótica do estilo, cerca de vinte anos depois de Hebdige (1979) ter analisado semioticamente a estética punk (Muggleton, 2000). 0 eclectismo é visto por Muggleton como um traço fundamental do estilo pós-moderno, considerando que o reordenamento, pelos actores, dos elementos subculturais em combinações novas e originais é um processo activo que não deve ser negligenciado

(Muggleton, 1997: 178). Critica, assim, perspectivas que, em virtude do processo pósmoderno de autonomização dos signos dos seus contextos culturais originais, não vêem no estilo pós-moderno mais que simulacros e pastiche (Ibidem: 176).

É importante questionar o uso dos conceitos de "resistência" e de "autenticidade" pelos autores da teoria original das subculturas, pois é aí detectável um certo idealismo; mas também é verdade que os estilos pós-modernos parecem ser, por vezes, um "mero jogo estilístico a ser jogado" (Ibidem: 180), ou seja, meras combinações lúdicas e desideologizadas num infinito de possibilidades oferecidas por um gigantesco 'Supermercado do Estilo' (Polhemus, 1997) onde tudo é inócuo. Para concluir, a teorização pós-moderna mais radical conduziu ao surgimento de estudos sobre o clubbing enformados por teorias do pós-sujeito e da pós-identidade, como será discutido adiante.

\subsection{Transformações de género}

20 As transformações que levaram à emergência das club cultures a partir da década de 1980 relacionam-se com alterações ao nível do género. McRobbie refere a emergência de novas feminilidades, segundo a autora simbolizada pela substituição da Jackie pela Just Seventeen como a revista para raparigas entre os 12 e os 16 anos mais vendida no Reino Unido (McRobbie, 1991, 1994; Hall \& Jefferson, 2006: xxiv). Esse processo terá posto em causa distinções clássicas, tais como entre subculturas baseadas na classe social e culturas juvenis comerciais, entre feminismo e feminilidade ou, ainda, entre autêntico e comercial (Ibidem).

Os conteúdos da Just Seventeen marcam a emergência de uma rapariga mais independente e individualizada, uma relativa ausência de "romance", a preponderância das fantasias 
dos mundos pop e da moda, a maior franqueza sexual, os prazeres de 'olhar' e a respectiva inscrição do corpo nas lógicas do consumo (Ibidem). McRobbie analisa a entrada destas jovens nos mercados de trabalho do 'novo consumo' ('new consumer labour market'), em que ocupam as funções associadas à venda e colocação de produtos no mercado. Há, nas análises de McRobbie, uma viragem das raparigas para as mulheres jovens e do lazer para os novos mercados de trabalho informais e novas indústrias culturais, focalizando-se esta autora, igualmente, nas contrariedades do 'pós-feminismo' (Ibidem).

\section{0 modelo de análise proposto}

\subsection{A plasticidade e o hibridismo do conceito de (sub)culturas club: abertura a conexões estruturais sem linearidades forçadas}

Em primeiro lugar, é importante conservar o que o quadro teórico subcultural clássico poderá continuar a ter de explicativo, ao mesmo tempo que se integram os novos elementos, as críticas e as expansões que os quadros pós-subcultural e das culturas club trazem.

Há que manter abertura à possibilidade de se encontrarem conexões entre realidades do clubbing e variáveis estruturais como o género, a classe e a etnicidade, ainda que considerando o fraccionamento do gosto e do consumo associado ao hedonismo das sociedades contemporâneas. Manifestamos reservas face às análises enquadradas por uma conceptualização pós-moderna das culturas club e das raves radicalmente hiperindividualizadas e assentes em teorias do pós-sujeito e da pós-identidade. Aí, o clubbing é apresentado como espaços e práticas onde as diferenças de classe, género e etnicidade desaparecem completamente e onde os participantes se tornam parte de uma espécie de "corpo sem órgãos" (Jordan, 1995)7.

As questões levantadas pelos pós-subculturalistas são relevantes, desde logo ao sugerirem que as subculturas são, em parte, uma construção teórica e totalizante, dado serem fruto de uma epistemologia realista (Muggleton, 1997: 183). Muggleton aponta, por exemplo, a dificuldade da teoria subcultural clássica, com a sua ênfase nas culturas juvenis de uma classe operária 'pura' (conceito associado a noções de autenticidade e resistência), em explicar a participação dos jovens de classe média nessas mesmas subculturas dos anos de 1960 e 70 e, simultaneamente, enquadrar esse fenómeno no quadro marxista subjacente a essa teoria (Ibidem: 182).

Por outro lado, não seguimos a linha pós-moderna/pós-estruturalista radical, pois é pertinente a afi rmação de Hollands de que se os pós-modernos não encontram desigualdades ou estratificação nas culturas juvenis é, pelo menos em parte, porque não as procuram (Hollands, 2002: 158, citado por Carrington e Wilson, 2004: 77). Hollands questiona ainda se "serão os exemplos pós-modernos mais representativos ou empiricamente demonstráveis (...) do que eram as subculturas das minorias?" (Ibidem). Propomos o conceito composto/híbrido de (sub)culturas club, pela sua plasticidade analítica e adaptabilidade à complexidade das realidades estudadas e às possíveis contradições a elas inerentes. Este conceito simboliza a abertura do quadro analítico aqui exposto face às possibilidades de se capturar empiricamente características quer subculturais, quer pós-subculturais e de carácter mais pós-moderno. Representa uma alternativa a uma concepção dualista entre diferentes teorias, sugerindo a possibilidade de haver uma linha contínua entre características subculturais e pós-subculturais, bem 
como de se encontrarem realidades híbridas e heterogéneas, em que elementos subculturais coexistem com elementos pós-subculturais. Este conceito tem um carácter aberto, não tendo uma filiação unívoca em qualquer das teorias aqui discutidas, embora denotando assumidamente uma precaução face às perspectivas radicalmente pósmodernas.

Concluindo, pretendemos propor um quadro teórico que, valorizando a subjectividade dos sujeitos, admita tanto a possibilidade de objectivação de conexões estruturais (homologias), como de não-linearidades e fragmentação, sem pretender forçar a realidade empírica a encaixar artificialmente em qualquer das perspectivas que estiveram na base da formulação do conceito de (sub)culturas club. Em seguida, explicaremos detalhadamente o modelo de análise proposto (Figura 1, página seguinte).

\subsection{Para uma segmentação e especificação mais precisas das fracções do clubbing}

Partindo do trabalho pioneiro sobre as club cultures de Thornton, tanto Pini como Hutton baseiam as suas pesquisas na segmentação do clubbing entre 'mainstream' e 'underground's. Todos estes estudos incidem sobre o segmento 'underground', cujos frequentadores caracterizam como hip em comparação com o segmento 'mainstream', associado à música house considerada mais 'comercial's. No segmento 'underground', o consumo dito 'recreativo' de drogas e uma afectividade dessexualizada contrastam com o consumo de álcool, com a maior rigidez e sexualização dos dress codes e com a lógica de “engate” da fracção 'mainstream' (Thornton, 1996; Pini, 2001; Hutton, 2004, 2006).

O conceito de capital subcultural, proposto por Thornton, é relevante. Ele é formulado para se compreenderem os valores e as hierarquias actuantes no interior das club cultures (Thornton, 1996: 10). A autora inspira-se em Bourdieu (1979), que estabelece uma relação entre o gosto e a estrutura social, fazendo o primeiro depender da segunda. 0 capital subcultural pode ser entendido como uma subespécie de capital actuante no seio de um subcampo particular (Thornton, 1996: 11). Sendo reconhecido e conferindo um determinado estatuto a quem o possui, o capital subcultural corresponde a uma determinada hipness subcultural, podendo ser objectifi cado (ter os últimos vinis ou CD, roupas e adereços) ou corporalizado (dominar a performatividade subcultural e "parecer que se nasceu para interpretar os últimos estilos de dança") (Ibidem: 11). Tal como o conceito de capital cultural é fulcral para compreender os processos de distinção analisados por Bourdieu, o de capital subcultural é útil para analisar como processos equivalentes ocorrem nos espaços do clubbing. A diferenciação entre 'mainstream' e 'underground' é, então, uma dimensão importante da segmentação das (sub)culturas club a ter em conta ${ }^{10}$. No entanto, tal não é de todo sufi ciente. Os conceitos de clubbing ou de raving, usados em muita literatura sobre o clubbing sem nenhuma especificação adicional (para além de 'underground'), parecem-nos demasiado abstractos, genéricos e homogeneizantes. 0 estudo das club cultures será enriquecido e a sua complexidade mais bem apreendida empírica e analiticamente se se efectuar uma segmentação mais fina e localizada do clubbing, isto é, distinguindo entre as diferentes fracções (associadas a subgéneros de música electrónica de dança) que o compõem num dado país ou região. $\mathrm{Na}$ investigação que originou o presente modelo analítico (cf. Lopes, Boia, Ferro, Guerra, 2010a e 2010b; Boia e Lopes, 2012 $2^{11}$ ) foram seleccionadas e analisadas fracções específicas do segmento dito 'underground' das (sub)culturas club, nomeadamente o drum'n'bass, o 
trance e o techno. Não foram, contudo, descuradas as trajectórias passadas das clubbers pelo house dito 'mainstream', nem a sua participação, por vezes híbrida e pendular entre tais fracções do 'underground', ou mesmo entre estas e o house ${ }^{12}$ - admitindo-se assim o cenário mais pós-estruturalista que prevê a autonomia relativa da variável gosto face à classe social, ou uma certa fragmentação/pulverização do próprio gosto.

A segmentação das (sub)culturas club a um nível mais micro permite também algo de verdadeiramente importante: desenvolver uma perspectiva comparativa entre as construções identitárias nas diferentes fracções analisadas. Tal possibilita encontrar eventuais homologias - ou a ausência delas - entre certas fracções do clubbing e determinadas classes sociais, configurações de género ou de etnicidade aos níveis extraclubbing. Estas problemáticas relacionam-se com a necessidade de se desenvolver uma perspectiva assente numa interseccionalidade múltipla entre as várias variáveis em jogo (género, classe social, etnicidade, gosto/consumo), aspecto que será discutido a seguir.

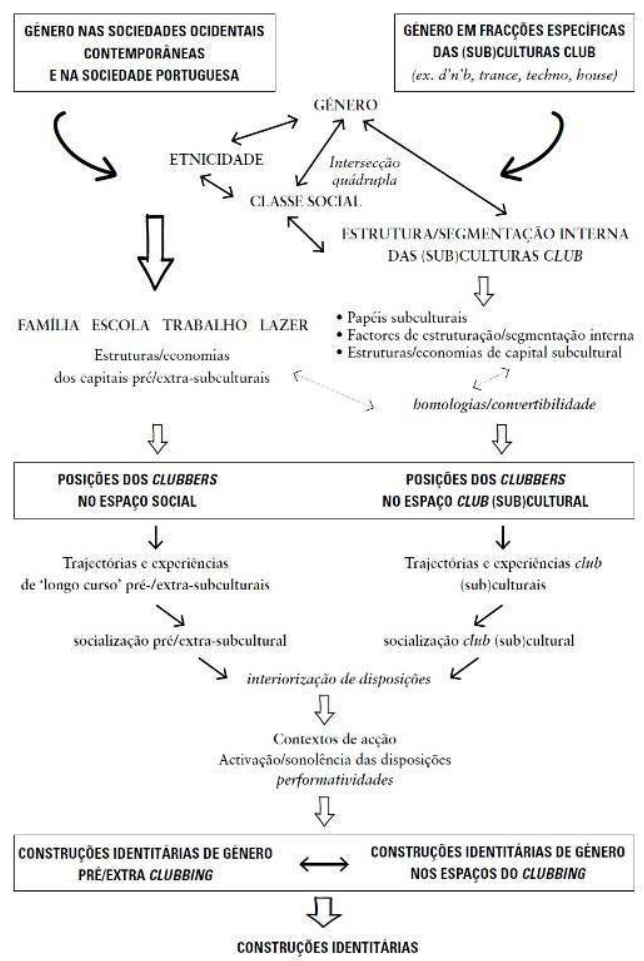

Figura 1. Modelo de análise das construções identitárias de género nas (sub)culturas club

\subsection{Para uma efectiva abordagem interseccional no estudo do clubbing}

No início, começámos por distinguir o conceito de "género" do de "sexo". É inegável que "feminilidades e masculinidades", como expressão das construções de género, são "multiformes no interior de cada ordem social e entre ordens sociais, em que se desenham muitos outros eixos de diferenciação, como a raça ou a classe" (Lovell, 2002: 319). Para além da necessidade de uma segmentação mais fina das fracções do clubbing, proceder a uma interseccionalidade efectiva entre variáveis é também fundamental para se compreender, com a devida profundidade, a complexidade do clubbing e dos fenómenos nele implicados. 
26 A perspectiva interseccional não privilegia necessariamente, à partida, qualquer variável. o género pode ser ou não a variável central na investigação. Neste caso foi, tendo sido sempre abordado em interseç̧ão com a variável classe social (e também, embora bastante menos, com a etnicidade), com os factores de estruturação interna inerentes a cada fracção das (sub)culturas club consideradas ${ }^{13}$, bem como com o gosto.

O modelo de análise proposto baseia-se, pois, numa intersecção múltipla entre todas estas variáveis. A abordagem interseccional é realçada, por exemplo, por Crenshaw (1989), McCall (2005) e Choo e Ferree (2010). Não a entendemos, no entanto, no sentido de tais intersecções gerarem necessariamente opressões, pois podem evidenciar também emancipações ou simplesmente dimensões de "modos de se ser" (sem implicações directas em termos de poder ou opressão). Encaramo-las, então, como produtoras de construções ou configurações identitárias.

Um aspecto que implica necessariamente a interseccionalidade é, por exemplo, a convertibilidade dos capitais. Mesmo se o capital subcultural não é, à partida, tão determinado pela estrutura de classes como o capital cultural (como em Bourdieu) (Thornton, 1996: 12) ${ }^{14}$, há que realçar vivamente as hipóteses de convertibilidade entre capitais intra e extra (ou pré) subculturais consideradas por Thornton (1996: 10-14, inspirada por Bourdieu, 1979). Podem existir não só homologias entre as estruturas/ economias relativas aos diferentes tipos de capitais extra-subculturais (económico, cultural, social e simbólico) e o capital intra-subcultural, mas também mecanismos que possibilitem processos de conversão de uns nos outros ${ }^{15}$.

A segmentação precisa das fracções clubbing e a interseccionalidade são recursos necessários para encontrar respostas para uma série de questões centrais, tais como: será que as construções identitárias resultantes das múltiplas possibilidades de intersecção são semelhantes no drum'n'bass, no trance ou no techno, por exemplo? Desde logo, será que os frequentadores destas diferentes fracções club (sub)culturais divergem entre si nas suas características sociais, tais como a origem e trajectória de classe e a respectiva socialização em termos de internalização de elementos identitários de género intersectados com os de classe e de etnicidade? E poderá haver, nos comportamentos e vivências que têm lugar nos diferentes espaços do clubbing (pista de dança, zonas VIP), graus distintos de homologias ou, pelo contrário, relações não lineares ou até subversões relativamente a condicionamentos produzidos por estruturas de classe e de género profundamente enraizadas na sociedade de um país ou uma região?

\subsection{Trajectórias biográficas, socialização e disposições}

Finalmente, a consideração das trajectórias biográficas de socialização e a internalização de disposições permitem efectivar a análise interseccional a um nível mais profundo. Considerando aspectos estruturais relativos às configurações de género nas sociedades estudadas (identidades, práticas, performances, divisão de trabalho, variados elementos estruturais de longo 'curso'), há que saber como as trajectórias e experiências de 'longo curso' pré e extra-club (sub)culturais das clubbers constroem em si mesmas certas identidades nos sujeitos. A família, a escola e o trabalho são instâncias de socialização centrais. Ao mesmo tempo, cada fracção do clubbing tem certas configurações de género inerentes, havendo também, por isso, que estudar as trajectórias e experiências dos participantes no seio das (sub)culturas club. Estas últimas são, elas próprias, uma instância de socialização importante. Em suma, há que inter-relacionar as dimensões pré/ 
extra-clubbing e intra-clubbing.

A sociologia das disposições é aqui um contributo teórico essencial. Produzidas pela posição objectiva dos sujeitos no espaço social, as disposições são matrizes internalizadas pelos sujeitos ao longo das suas trajectórias de socialização, que depois os predispõem para e geram certos tipos de acções, práticas e juízos de valor (Bourdieu, 1972, 1979). No estudo por nós desenvolvido, apropriámos e aplicámos a metodologia dos 'retratos sociológicos' de Lahire (2004), cuja teoria disposicional enfatiza uma sociologia à escala individual que procura compreender como múltiplos contextos de socialização podem produzir, num mesmo sujeito, disposições mais ou menos plurais e heterogéneas e não necessariamente coerentes entre si. Essas disposições são depois activadas ou não (mantidas em sonolência) pelos contextos de acção referentes às diferentes esferas de vida em que o sujeito se situa em cada momento (Lahire, 2001, 2004, 2005). A análise das variações intra e inter-individuais, bem como das singularidades e das regularidades é aqui importante (Ibidem). A inter relação das dimensões pré/extra e intra-clubbing das identidades e conjuntos disposicionais de cada sujeito pode revelar quer homologias e consonâncias, quer diferenças e dissonâncias entre estes três níveis. Há que dar, igualmente, a devida atenção às tensões e aos dilemas inerentes aos casos de sujeitos que têm neles interiorizadas disposições plurais, heterogéneas e contrastantes. Também a performatividade - ela própria constitutiva das identidades (por exemplo, de género - cf. Butler, 1988) - deve ser considerada.

\section{Breve olhar sobre alguns resultados da investigação}

31 Empiricamente, os resultados do nosso estudo (Lopes et al., 2010a e 2010b;

Boia e Lopes, 2012 $)^{16}$ sugerem a existência de homologias relativas entre, por um lado, as segmentações internas entre fracções do clubbing e, por outro, segmentações estruturais extra-clubbing relativas a outras esferas da sociedade (classes e meios sociais, capital escolar, etnicidade, género). Por exemplo, drum'n'bass surgiu associado aos centros urbanos, com frequentadores escolarizados e pertencentes às classes médias, enquanto o techno, com festas de grande dimensão deslocalizadas dos centros e atraindo frequentadores de diferentes regiões do país, se caracterizou por uma certa associação a clubbers oriundos de meios mais populares, possuidores de menos capital académico e, frequentemente, residentes nas periferias urbanas (os ditos "bairros problemáticos") ${ }^{17}$. Nos eventos de cada fracção do clubbing considerados, os frequentadores 'legítimos' detectam e, como diria Goffman e os outros interaccionistas simbólicos, 'etiquetam' os 'intrusos' vindos de outras fracções, como "betinhos" ou como "gunas" (Ibidem).

Preocupados em evitar que o quadro teórico de partida criasse uma "circularidade" viciosa entre teoria e observação (Pinto, 1984; Almeida e Pinto, 1986) ${ }^{18}$, a verdade é que a 'erosão' de diferenças de género no clubbing "underground" descrita por Pini (2001) e o papel positivo do risco (associado ao uso "recreativo" de certas drogas e à sexualidade) na construção identitária das mulheres referido por Hutton $(2004,2006)$ nem sempre se verificaram empiricamente nas realidades observadas. Pelo contrário, o nosso estudo mostra que as drogas consumidas e os respectivos padrões de consumo, bem como os níveis de risco associado às drogas, sexualidade e violência, diferem muito entre as fracções do clubbing estudadas.

Os resultados revelam uma clara influência das disposições de classe social em intersecção com o género e respectivas trajectórias de 'longo curso' pré-clubbing sobre as vivências, 
comportamentos e experiências que têm lugar nos eventos clubbing, se bem que de modo nem sempre linear e por vezes até com subversões. Noutros casos, as trajectórias e as disposições club (sub)culturais também exercem uma influência activa sobre as dimensões identitárias e práticas que ocorrem nas esferas de vida e nos contextos de acção extraclubbing.

34 A intersecção aprofundada entre variáveis revelou realidades complexas. Por exemplo, o estilo 'unissexo' no techno coexiste, paradoxalmente, com a activação de disposições e reprodução de identidades de género de 'meio popular' durante os eventos clubbing, com um controlo masculino tradicional sobre as mulheres (do qual as mulheres procuram fugir, delineando estratégias para irem autonomamente às festas, de autocarro, em grupos sem homens), ou a ocorrência de conflitos entre casais ("filmes") devido à possessividade conjugal e ciúmes. Em comparação, saliente-se a maior simetria nas relações de género no drum'n'bass - apesar da maior polarização entre estilos de apresentação (roupas, maquilhagem, etc.) masculinos e femininos, ou os sinais de emergência de novas masculinidades no trance que apontam também para tal simetria.

Refira-se a "mágica" pós-moderna de certas salas VIP, descrita por uma frequentadora de techno oriunda da periferia do Porto, onde, relata, as "tias viravam peixeiras" e as "peixeiras viravam tias" (subversões de fronteiras e hierarquias entre classe ou estratos, apesar de se observar a convertibilidade dos capitais nos convites que essas "tias" e respectivos companheiros lhe faziam para os acompanhar aos seus apartamentos na chic Foz do Porto, onde - diziam "não lhes faltaria nada").

A simbologia do MDMA como "droga do amor" e a mistura frequente entre álcool e drogas em todas as fracções estudadas levam a conceptualizar um 'underground'(?) localizado, contrastante com as realidades do clubbing descritas na literatura anglo-saxónica. Estes estudos sugerem a existência, aí, de um afecto dessexualizado como resultado da ingestão de ecstasy, bem como uma ausência de consumo de álcool. Esta última substância é apontada como levando mais facilmente a uma falta de controlo, por parte da mulher, sobre a sua própria sexualidade e, daí, como sendo especialmente potenciadora de risco e de perigo ${ }^{19}$. A mistura na ingestão de substâncias nas realidades por nós estudadas levanta novas questões quanto ao risco. É vital, pois, considerar as dimensões 'locais' e 'translocais' de cada "cena" ('scene' - cf. Bennett, 2004).

Torna-se evidente que a segmentação precisa das fraç̧ões do clubbing e uma perspectiva comparativa enriquecem e potenciam a análise interseccional e a apreensão analítica da pluralidade e complexidade destas realidades. Os resultados do nosso estudo confirmam assim a heuristicidade e pertinência do quadro de análise proposto.

\section{Conclusão: para uma especificação empírica e localizada do género e das feminilidades}

38 Haverá, no clubbing, uma 'erosão' de diferenças produzidas pelas variáveis clássicas como a classe social, o género ou a etnicidade? Será a dimensão pós-identitária das vivências club (sub)culturais (que não rejeitamos) completamente neutralizadora de diferenças sociais naqueles espaços e contextos de acção?

Quanto ao género, a análise de Pini (2001) é algo ambivalente, sugerindo um certo grau de 'desgenderização', em linha, por exemplo, com as ficções e utopias feministas de Haraway (1991) ou de Braidotti (1991). No entanto, funcionará necessariamente e sempre o clubbing 
como "espaço de experimentação de novas feminilidades" (Pini, 2001) e, se sim, será que tal acontece do mesmo modo nas diferentes fracções club (sub)culturais e nas frequentadoras com diferentes posições e trajectórias pré e extra-clubbing? Questões semelhantes a esta, implicando as variáveis género, classe social, etnicidade e gosto, devem ser colocadas.

As respostas dependem das especificidades das fracções do clubbing estudadas, dos seus frequentadores, das sociedades e dos espaços que se inserem - por exemplo, Romo (2004) mostra que em Espanha, num certo período, o aumento da violência em eventos de música electrónica de dança produziu um regresso às feminilidades tradicionais (ressurgimento das "festeras").

No clubbing, mulheres e homens podem encontrar espaços alternativos de construção identitária e de relacionamento inter e intragéneros, estribados em pressupostos 'marginais' de acumulação de capital social. Também podem reproduzir identidades, relações sociais e de poder entre géneros, profundamente enraizadas 'antes' e fora dos espaços do clubbing. As festas de música electrónica são relatadas, frequentemente, como espaços de liberdade, de aventura, de prazer. Podem ser espaços de emancipação mas também de reprodução de poderes, de constrangimentos e desigualdades, onde o grau de risco se pode converter em perigo. Será que no clubbing 'underground' o risco é sempre e necessariamente um elemento positivo na estruturação da identidade e construção de feminilidades (Hutton, 2004, 2006)? Nem sempre e, quando o é, é provável que tal não aconteça sempre da mesma maneira. O risco pode funcionar quer positiva quer negativamente nas vivências das mulheres clubbers. Toda esta multiplicidade de situações é evidenciada nos resultados da nossa investigação.

Magalhães (2002) propõe o uso do conceito de agência feminina/feminista, não deixando de o problematizar face às críticas pós-estruturalistas (cf. também Arnot e Dillabough, 2002; e Young, 1995, já citados). Isso alerta-nos para os riscos de 'essencialização' da identidade, nomeadamente da universalização do conceito de "mulher". O mesmo pode acontecer, sugerimos, ao aceitar-se uma única noção generalizada de mulher clubber. Este é um risco presente na literatura específica sobre as experiências das mulheres no clubbing discutida ao longo deste texto.

Para evitar uma homogeneização artificial das experiências e a universalização tácita de um certo tipo de mulher clubber, de feminilidade e de construção de género, é necessário proceder a uma segmentação mais fi na entre fracções do clubbing (análises comparativas são sempre úteis), desenvolvendo-se uma abordagem interseccional que considere as trajectórias pré-clubbing, bem como a inter-relação entre as construções identitárias intra e pré/extra-clubbing. Tudo isto permite especificar empiricamente diferentes construções de género e feminilidades de um modo localizado e concreto, com respeito pela pluralidade de casos e pela complexidade da realidade.

Como nota final, realçaríamos novamente que esta proposta teórica é aplicável não só em estudos que privilegiem o género (ou outra variável), mas também naqueles em que seja dada igual importância às múltiplas variáveis em jogo. 


\section{BIBLIOGRAPHY}

ALMEIDA, J. F., PINTO, J. M. (1986), “Da teoria à investigação empírica. Problemas metodológicos gerais”, in A. S. Silva e J. M. Pinto (orgs.), Metodologia das Ciências Sociais. Porto: Afrontamento: 55-78.

ARNOT, M., DILLABOUGH, J. (2002), "Reformular os debates educacionais sobre a cidadania, agência e identidade das mulheres", Ex Aequo, n.. 7, FPCEUP.

BENNETT, A. (1999), "Subcultures or neo-tribes? Rethinking the relationship between youth, style and musical taste", Sociology, Vol. 33, n. 3: 599-617.

BENNETT, A. (2004), "Consolidating the music scenes perspective", Poetics, n. 0 32: 223-234.

BENNETT, A., KAHN-HARRIS, K. (2004), After Subculture. Palgrave Macmillan.

BOIA, P. S., LOPES, J. T. (2012), “Do 'flashar' dos 27 à techno-clubber de 40: retrato sociológico de Maria", in J. T. Lopes (org.), Registos do Actor Plural: Bernard Lahire na sociologia portuguesa. Porto: Afrontamento : 57-90.

BOURDIEU, P. (1972), Esquisse d'une théorie de la pratique. Genève: Editions Droz.

BOURDIEU, P. (1976), “Quelques propriétés des champs”, in Bourdieu, P., Questions de sociologie.

Paris: Minuit : $113-120$.

BOURDIEU, P. (1979), La Distinction. Critique sociale du jugement. Paris: Les Editions de Minuit. BRAIDOTTI, R. (1991), Nomadic Subjects: Embodiment and sexual difference in contemporary Feminist Theory. New York: Columbia University Press.

BUTLER, J. (1988), "Performative acts and gender constitution: an essay in phenomenology and feminist theory", Theatre Journal, Vol. 40(4): 519-531.

CARRINGTON, B., WILSON, B. (2004), "Dance Nations: rethinking youth subcultural theory", in A. Bennett, K. Kahn-Harris (orgs.), After Subculture. Palgrave Macmillan.

CHOO, H., FERREE, M. (2010), “Practicing intersectionality in Sociological Research's critical analysis of inclusions, interactions, and institutions in the study of inequalities", Sociological Theory, 28:2: 129-149.

COHEN, P. (1997) [1972], "Subcultural confl ict and working-class community", in K. Gelder and S. Thornton (orgs.), The Subcultures Reader. London and New York: Routledge: 90-99.

CRENSHAW, K. (1989), Demarginalizing the Intersection of Race and Sex: A black feminist critique of antidiscrimination doctrine, feminist theory and antiracist politics. Chicago: The University of Chicago Legal Forum: 139-167. FERREIRA, M. L. (2001), “Reflexões sobre o conceito de género", in M. L. Ribeiro (org.), Pensar no Feminino. Lisboa: Colibri.

GIDDENS, A. (1996), Novas Regras do Método Sociológico. Lisboa: Gradiva.

GIDDENS, A. (2000), Dualidade e Estrutura, Agência e Estrutura. Oeiras: Celta.

HABERMAS, J. (1984), Mudança Estrutural da Esfera Pública. Rio de Janeiro: Edições Tempo Brasileiro.

HALL, S. e JEFFERSON, T. (orgs.) (2006) [1976], Resistance through Rituals (ed. de 2006 com novo prefácio). Abingdon: Routledge.

HARAWAY, D. (1991), “A Cyborg Manifesto”, in Haraway, D., Simians, Cyborgs and Women. New York: Routledge.

HEBDIGE, D., (1979), Subculture: the Meaning of Style. Londres: Methuen.

HOLLANDS, R. (2002) "Divisions in the dark? Youth cultures, transitions and segmented consumption spaces in the night-time economy", Journal of Youth Studies, Vol. 5, Issue 2: 153-171. HUTTON, F. (2004), "Up for it, mad for it? Women, drug use and participation in club scenes", Health, Risk and Society, Vol. 6. 
HUTTON, F. (2006), Risky Pleasures? Club cultures and feminine identities. Hampshire: Ashgate. JACKSON, P. (2003), Inside Clubbing. Sensual experiments in the art of being human. Oxford/NY: Berg. JORDAN, T. (1995), "Collective bodies: raving and the politics of Gilles Deleuze and Felix Guattari", Body and Society, Issue 1, Vol. 1.

LAHIRE, B. (2001), O Homem Plural - As molas da acção. Lisboa: Piaget.

LAHIRE, B. (2004), Retratos Sociológicos - Disposições e variações individuais. São Paulo: Artmed Editora.

LAHIRE, B. (2005), "Patrimónios individuais de disposições: para uma sociologia à escala individual”, Sociologia - Problemas e práticas, n.․ 49.

LINCOLN, S. (2004) “'Teenage girls' 'Bedroom Culture': Codes versus Zones”, in A. Bennett e K. Kahn-Harris (orgs.), After Subculture. Palgrave Macmillan.

LOPES, J. T. (2000), A Cidade e a Cultura. Porto: Afrontamento.

LOPES, J. T. (coord.), BOIA, P. S., FERRO, L., GUERRA, P. (2010a), Género e Música Electrónica de Dança: Experiências, percursos e 'retratos' de mulheres clubbers. Lisboa: CIG.

LOPES, J. T., BOIA, P. S., FERRO, L., GUERRA, P. (2010b), “Género e música electrónica de dança: experiências, percursos e 'retratos' de mulheres clubbers", Sociologia, Problemas e práticas, n.․ 62: $35-56$.

LOVELL, T. (2002), "Teoria social feminista", in B. S. Turner (org.), Teoria Social. Algés: Difel. MAFFESOLI, M. (1987), O Tempo das Tribos. Rio de Janeiro: Forense-Universitária.

MAGALHÃES, M. J. (2002), “Em torno da definição do conceito de agência feminista”. Ex Aequo, n.o 7, FPCEUP, 189-198.

MALBON, B. (1999), Clubbing. Dancing, ecstasy and vitality. London/NY: Routledge.

MARTIN, G. (2004), "New social movements and democracy”, in M. J. Todd e G. Taylor (orgs.), Democracy and Participation: Popular protest and new social movements. Londres: Merlin Press: 29-54. McCALL, L. (2005), "The complexity of intersectionality", Signs: Journal of women in culture and society. Vol. 30(3): 1771-1800.

McROBBIE, A. (1991), Feminism and Youth Culture: from Jackie to Just Seventeen. Londres: Macmillan. McROBBIE, A. (1994), Postmodernism and Popular Culture. Londres e N. I.: Routledge.

McROBBIE, A., GARBER, J. (2006), "Girls and subcultures”, in S. Hall e H. Jefferson (orgs.), Resistance through Rituals. Abingdon: Routledge: 177-188.

MEASHAM, F., HADFIELD, P. (2009), "Everything starts with an 'E': Exclusion, ethnicity and elite formation in contemporary English clubland", Adicciones, 21(4): 363-386. MUGGLETON, D. (1997) "The Post-subculturalist", in S. Redhead et al. (orgs.), The Clubcultures Reader. Oxford: Blackwell: 185-203.

MUGGLETON, D. (2000), Inside Subculture: The Posmodern meaning of style. Oxford/ N. I.: Berg. PINI, M. (2001), Club Cultures and Female Subjectivity: The move from home to house. N. I: Palgrave. PINTO, J. M. (1984), “Questões de metodologia sociológica”, I. Cadernos de Ciências Sociais, n.ำ: 5-42. POLHEMUS, T. (1997) “In the supermarket of style", in S. Redhead et al. (orgs.), The Clubcultures Reader. Oxford: Blackwell: 130-133.

REDHEAD, S. (1997), Subculture to Clubcultures. Oxford: Blackwell.

REDHEAD, S. et al. (org.) (1997), The Clubcultures Reader. Oxford: Blackwell.

ROBERTS, M. (2005), "Notes on the global underground", in K. Gelder (org.), The Subcultures Reader (2. e ed.). Routledge.

ROMO, N. (2004), “Tecno y baile. Mitos y realidades de las diferencias de género”, Estudios de juventud, n.․ 64/04.

THORNTON, S. (1996), Club Cultures - Music, media and subcultural capital. Middletown: Wesleyan University Press.

WILLIS, P. (1977), Learning to Labour. Farnborough: Saxon House. 
YOUNG, I. M. (1995), “Gender as seriality: thinking about women as a social collective”, in L. Nicholson e S. Seidman (orgs.), Social Postmodernism. Cambridge: Cambridge University Press.

\section{NOTES}

[5․ㄹ. Texto escrito em conformidade com as normas anteriores ao Acordo Ortográfico de 1990.

1. Este artigo resulta do projecto de investigação "Construções identitárias de género nas (sub)culturas clubbers" (PIHM/SOC/63599/2005), co-fi nanciado pela FCT e pela CIG, e realizado no Instituto de Sociologia da Faculdade de Letras da Universidade do Porto em 2007-08. A equipa foi constituída por João Teixeira Lopes (coordenador), Paula Guerra, Lígia Ferro e Pedro dos Santos Boia. Este foi um estudo qualitativo, fundamentalmente baseado em incursões etnográficas, observação directa e entrevistas.

2. Malbon salienta a vitalidade, a dança e as experiências extáticas.

3. o jogo de palavras no subtítulo do livro de Pini, The move from home to house, é bem conseguido.

4. Este é um outro aspecto do referido jogo de palavras

5. Primeira edição originalmente publicada em 1976

6. A ideia de homologias também está presente na teoria dos campos de Bourdieu (homologia entre os campos) (por exemplo, Bourdieu, 1976, 1979).

7. Para uma breve discussão crítica destes trabalhos, cf. Pini, 2001, pp. 6-7

8. Sendo baseada nos termos usados pelos próprios clubbers - nos seus 'etnométodos', podemos dizer -, há que ter o cuidado para não reifi car as noções de 'mainstream' e 'underground' e o respectivo dualismo.

9. Como mostra Thornton, a un-hipness atribuída aos clubes 'mainstream' é associada ao género feminino e a hipness do segmento 'underground' ao género masculino (Thornton, 1996: 87-115), sendo este um julgamento que reflecte, obviamente, a perspectiva dos clubbers do segmento dito 'underground'. Apesar disso, é no segmento 'underground' que, segundo Pini (2001), as mulheres têm maior liberdade para experimentarem novas feminilidades.

10. Refira-se também a segmentação entre os produtores/organizadores e os frequentadores.

11. Desenvolvimentos recentes na literatura sobre o clubbing demonstram também preocupação com A necessidade de questionar a homogeneização do fenómeno (por ex., Measham e Hadfield, 2009).

12. A fluidez relativa das fronteiras entre fracções das (sub)culturas club, bem como os constantes e múltiplos fenómenos de mutação e de hibridização entre subgéneros musicais e respectivas características club subculturais, são aspectos igualmente importantes.

13. Em cada fracção analisada pode-se considerar, para além do capital subcultural e da segmentação entre a produção/organização e o consumo, a respectiva panóplia de papéis club (sub)culturais, as características estéticas da música e dos artefactos materiais e visuais, as substâncias ingeridas pelos participantes, os padrões de comportamento, as performatividades, os estilos e formas de apresentação do eu, etc.

14. Subjacente a esta questão está a noção das club cultures como culturas baseadas no gosto, concebido como variável autónoma e não determinado, de um modo linear, pela estrutura de classes sociais.

15. O "postulado da convertibilidade entre os diferentes tipos de capital (...) é", para Bourdieu, "condição da redução do espaço à unidimensionalidade" (Bourdieu, 1979: 137). São óbvias as implicações e consequências deste processo ao nível da estruturação e estratificação social de poder.

16. Apenas se discutem aqui, de um modo muito breve e simplificado, alguns aspectos. Convidamos o leitor a explorar os resultados completos nas outras publicações produzidas no 
âmbito deste projecto de

investigação.

17. As observações feitas sugerem também a presença de uma considerável proporção de afroportugueses em festas techno.

18. Se bem que nenhum quadro teórico seja absolutamente 'neutro' - os conceitos e hipóteses considerados à partida condicionam o que se irá encontrar e foi já mencionada a nossa precaução face às perspectivas radicalmente pós-modernas.

19. De acordo com a observação por nós levada a cabo, os consumos de substâncias, diferindo conforme as fracções, são mais moderados no drum'n'bass ou no trance do que no techno. Surgiram por parte das frequentadoras do techno relatos de abusos sexuais e violações associados aos consumos. Apesar disso, refiram-se relatos de frequentadores do drum'n'bass (onde supostamente os consumos seriam mais controlados), que passaram de um uso 'recreativo' de certas drogas ao consumo de heroína, que começaram a ir comprar a bairros "problemáticos".

\section{ABSTRACTS}

A partir de uma investigação das construções identitárias de género das mulheres nas (sub)culturas club associadas à música electrónica de dança em Portugal, este artigo pretende contribuir para os clubbing studies, propondo um modelo de análise aplicável ao estudo de diversas realidades, espaços e fracções do clubbing. Discutindo a literatura das teorias das subculturas, pós-subculturas e club cultures, as respectivas transformações sociais e implicações de género, delineamos um quadro analítico híbrido e plástico, capaz de apreender a complexidade destas realidades. É enfatizada a necessidade de: i) segmentar com precisão as fracções das (sub)culturas club; ii) efectivar uma interseccionalidade múltipla entre diferentes variáveis (género, classe social, etnicidade, segmentação interna do clubbing, gosto); e, por último, iii) analisar as trajectórias biográficas e de socialização das clubbers no âmbito de uma sociologia das disposições. Estes aspectos são essenciais para uma especificação empírica e localizada das múltiplas construções de género e feminilidades, evitando-se assim a universalização tácita de uma noção e experiência unívocas de "mulher clubber".

Resulting from a research on the gender identity constructions of women in club (sub)cultures (associated with electronic dance music) in Portugal, this article aims to contribute to clubbing studies by proposing an analytical framework useful for the study

of different realities, spaces and fractions of clubbing. After discussing literature on the theories of subcultures, post-subcultures and club cultures, and the respective social changes and gender implications, we present a hybrid and plastic framework, capable of helping us explore the complexity of these realities. The article stresses the need to: i) segment with precision the club (sub)cultures fractions under study, ii) explore the multiple intersectionality between different variables (gender, social class, ethnicity, internal segmentation of club (sub)cultures, taste), and fi nally iii) analyse the clubbers' biographic and socialisation trajectories within the scope of the sociology of dispositions. These aspects are essential for an empirically and localised specifi cation of the multiple constructions of gender and femininities, thus avoiding the tacit universalisation of a single notion and experience of "female clubber". 
À partir d'une recherche sur les constructions identitaires des femmes dans les (sous-)cultures club liés à la musique électronique de danse au Portugal, cet article vise à

contribuer aux clubbing studies en proposant un modèle d'analyse utile pour l'étude des différentes réalités, espaces et fractions du clubbing. Moyennant la discussion de la littérature concernant les théories des sous-cultures, post-sous-cultures et cultures club, leurs transformations sociales et de genre, nous proposons un cadre analytique hybride et plastique, capable de saisir la complexité de ces réalités. L'article met l'accent

sur la nécessité: i) de segmenter avec précision les fractions de (sous-)cultures club, ii) d'explorer l'intersectionnalité multiple entre différentes variables (genre, classe sociale,

ethnicité, segmentation interne des (sous-)cultures club, goût) et, enfi n, iii) d'analyser les trajectoires biographiques et la socialisation des clubbers dans le cadre d'une sociologie des dispositions. Ces aspects sont essentiels pour une spécifi cation empirique des constructions de genre et féminités multiples, évitant de cette façon l'universalisation tacite

d'une notion et d'une expérience univoques de la "femme clubber."

\section{INDEX}

Mots-clés: Clubbing; cultures club; sous-cultures; genre; intersectionnalité; dispositions.

Keywords: Clubbing; club cultures; subcultures; gender; intersectionality; dispositions.

Palavras-chave: Clubbing, música de dança, género, disposições, interseccionalidade.

\section{AUTHORS}

\section{PEDRO BÓIA}

Universidade do Porto

Investigador do Instituto de Sociologia da Universidade do Porto e do Instituto de Etnomusicologia (INET). Endereço de correspondência: Instituto de Sociologia da Faculdade de Letras da Universidade do

Porto. Via Panorâmica, s/n - 4150-564 Porto

psantosboia@gmail.com

\section{LÍGIA FERRO}

Investigadora do Centro de Investigação e Estudos de Sociologia (CIES, ISCTE-IUL) e investigadora associada do Instituto de Sociologia da Universidade do Porto (IS-UP). Endereço de correspondência: Edifício ISCTE, Av. das Forças Armadas - 1649-026 Lisboa ligia.ferro@iscte.pt

\section{JOÃO TEXEIRA LOPES}

Professor Catedrático e Presidente do Departamento de Sociologia da Faculdade de Letras da Universidade do Porto. Endereço de correspondência: Faculdade de Letras da Universidade do Porto. Via Panorâmica, s/n - 4150-564 Porto jlopes@letras.up.pt 